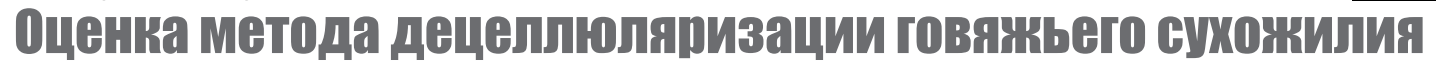 при разработке протеза крестообразной связки
}

\author{
М.В. Гурин ${ }^{\bowtie}$, А.А. Венедиктов \\ ООО «Кардиоплант», \\ 440004, Россия, Пенза, Центральная ул., д. 1в, корп. 2
}

Автор, ответственный за переписку: Максим Вячеславович Гурин, инженер-исследователь,

ООО «Кардиоплант», gmv7981@ mail.ru

\section{Аннотация}

Введение. Связки выполняют важнейшую роль в организме, соединяя кости между собой. Разръьвь связок представляют собойнаиболеечастые проявлениясеръезныхкостно-мышечных травм. Особенно это актуалъно для передней крестообразной связки коленного сустава. В травматологии и ортопедии фуунииональное восстановление связок может быть достигнуто при использовании аутотрансплантации, синтетических и биологических протезов. Большой интерес для хирургов представляет использование протезов из биотканей животного происхождения, так как они легкодоступны и при достижении качественной обработки безопасны, сохраняя при этом свою естественную структуру и прочность.

Цель исследования. Децеллюляризовать говяжве сухожилие в соответствии с нашей первоначально разработанной техникой и исследовать его эбббективность с точки зрения наличия клеточных элементов, а также бизических и механических параметров материала.

Материал и методы. Для изготовления прототипа изделия связочного протеза мъь разработали технологию обработки сухожилия крупного рогатого скота, как наиболее схожего по структуре материала, включая его механическую обработку, химико-ббизические методы обработки и специальную обработку сверхкритическим фблюидом диоксида углерода, содержащим неионогенное поверхностно активное вещество Твин-80 для децеллюляризации и извлечения органических компонентов в дополнение к коллагеновому каркасу при сохранении прочностных свойств. Бъли выполнены гистологические исследования для проверки остатков клеточных элементов, а также измерения бизико-механических свойств материала.

Результаты. Гистологическое исследование показало, что после всех методов обработки в материале обнаруживались 0-2 клетки в поле зрения. Прочностные характеристики материала составляли 503 кгс / мл ${ }^{2}$ до обработки и 605 кас/м. $^{2}$ после обработки.

Заключение. Данные, полученные в ходе исследования, подтверждают, что произведенная обработка качественно повлияла на выведение клеток, не ухудиила и даже повысила механическую прочность материала. Требуется дальнейшее изучение биосовместимъх свойств материала.

Ключевые слова: протез связки, децеллюляризация, сухожилие, ксенотрансплантат, биосовместимость, сверхкритический фрлюид диоксида углерода

КонФликт интеРЕсов Авторы заявляют об отсутствии конфлликта интересов

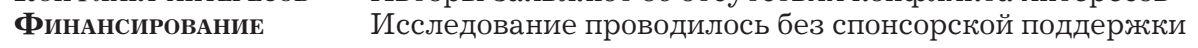

Для цитирования: Гурин М.В., Венедиктов А.А. Оценка метода децеллюляризации говяжьего сухожилия при разработке протеза крестообразной связки. Трансплантология. 2020;12(4):286-294. https://doi.org/10.23873/2074-0506-2020-12-4-286-294 


\title{
Evaluation of the bovine tendon decellularization method in the development of a cruciate ligament prosthesis
}

\author{
M.V. Gurin $\bowtie$, A.A. Venediktov \\ LLC "Cardioplant", \\ $1 v$ Bldg. 2 Centralnaya St., Penza 440004 Russia \\ Corresponding author: Maksim V. Gurin, Research Engineer, LLC "Cardioplant", gmv7981@ mail.ru
}

\begin{abstract}
Alsstract
Introduction. Ligaments play a critical role in the body, linking bones together. Ligament ruptures are the most common manifestations of serious musculoskeletal injuries. This is especially true for the anterior cruciate ligament of the knee joint. In trauma surgery, orthopedics, the ligament functional recovery can be achieved by using tissue autografting, synthetic and biological prostheses. Of great interest to surgeons is the use of prostheses made of biological tissues of animal origin, since they are easily available and, when high-quality processing is achieved, they are safe, retaining their natural structure and strength.

Purpose of the study. To decellularize the bovine tendon according to our originally developed technique and to investigate its efficacy in terms of the presence of cellular elements and physical and mechanical parameters of the material.

Material and methods. To manufacture the prototype of the ligament prosthesis product, we developed the technique for processing the bovine tendon, as the most similar material by structure, including its mechanical processing, chemical and physical processing methods and a special treatment with supercritical carbon dioxide fluid containing nonionic surfactant Tween-80 for decellularization and extraction of organic components in addition to collagen framework, while maintaining strength properties. Histological studies were performed to check for the residues of cellular elements, and the measurements of the physical and mechanical properties of the material were made.

Results. Histological examination of the material showed that after processing, $0-2$ cells in the field of view were found in the material. The strength properties of the material were $503 \mathrm{kgf} / \mathrm{mm}^{2}$ before processing and $605 \mathrm{kgf} / \mathrm{mm}^{2}$ after processing.

Conclusion. The data obtained in the study confirmed that the processing performed qualitatively affected the elimination of cells, did not worsen but even increased the mechanical strength of the material. Further study of the biocompatible properties of the material is required.
\end{abstract}

Keywords: ligament prosthesis, decellularization, tendon, xenograft, biocompatibility, supercritical carbon dioxide fluid

CONFLICT OF INTERESTS Authors declare no conflict of interest

FINANCING The study was performed without external funding

For citation: Gurin MV, Venediktov AA. Evaluation of the bovine tendon decellularization method in the development of a cruciate ligament prosthesis. Transplantologiya. The Russian Journal of Transplantation. 2020;12(4):286-294. (In Russ.). https://doi. org/10.23873/ 2074-0506-2020-12-4-286-294

ПКС - передняя крестообразная связка

СКФ-СО 2 - сверхкритический фрлюид диоксида углерода

\section{Введение}

Связки выполняют важнейшую роль в организме, соединяя кости между собой. Они представляют собой полосы плотной соединительной ткани, преимущественно состоящие из белков коллагена и эластина.

Наибольшее значение в травматологии имеет передняя крестообразная связка (ПКС), направленная от бедренной к большеберцовой кости. Она имеет среднюю длину 32 мм и ширину 7-12 мм. Волокна внутри связки закручены под углом в $110^{\circ}$. Связка является главной структу- рой в коленном суставе, так как она удерживает голень от смещения вперед и внутрь. До 50-70\% всех травм опорно-двигательного аппарата составляют травмы коленного сустава; в основном у спортсменов - представителей физически сложных видов спорта, в том числе единоборств.

Разрыв ПКС является одной из наиболее частых причин возникновения серьезной костно-мышечной травмы, характерной для физически активных людей [1]. Теоретически максимально допустимая нагрузка на ПКС находится в пределах от $734 \mathrm{H}(73,4$ кгс/мм² $)$ до $1725 \mathrm{H}$ $\left(172,5\right.$ кгс/ мм $\left.^{2}\right)$, а среднее значение нагрузки на 
ПКС для человека от 17 до 35 лет равно $1700 \mathrm{H}$ $\left(170\right.$ кгс $\left./ \mathrm{Mm}^{2}\right)$ [2].

Обычно повреждениям коленного сустава подвержены лица наиболее трудоспособного возраста, притом мужчины травмируются в среднем в 2 раза чаще, чем женщины [3]. Совершенствование технологии пластики ПКС, а также других видов связок коленного сустава либо других суставов имеет высокую актуальность для травматологов-ортопедов на протяжении многих десятилетий.

Основной причиной интереса к проблеме разрыва связок явилась не только сохраняющаяся тенденция к увеличению количества травм коленного сустава, сопровождавшихся разрывами связок, появление новых способов пластики и их технического оснащения, но и сорормировавшаяся в профессиональном сообществе потребность определить преимущества, особенности и перспективы создаваемых новых технологий [4].

В артроскопической хирургии актуальным в настоящее время остается вопрос выбора трансплантата для пластики. Для этой цели используют ауто- и аллотрансплантаты, а также синтетические протезы. Из аутотканей наиболее пригодными для восстановления связок являются средняя треть собственной связки надколенника с костными блоками, сухожилия «гусиной лапки» - полусухожильной и нежной мышц бедра, а также часть сухожилия четырехглавой мышцы бедра с костным блоком. В качестве аллотрансплантатов применяются консервированные различными методами донорские сухожилия. Искусственные протезы связок изготавливаются из очень прочных синтетических материалов, таких как капрон, лавсан, перилен, дакрон и полиэстер. $\mathrm{K}$ недостаткам аутопластики можно отнести увеличение длительности оперативного вмешательства и его травматичность, наличие донорской раны и связанных с ней осложнений.

Несмотря на значительные преимущества синтетических протезов, таких как: минимизация травмы, ранняя активизация больных, возможность нагрузки и движения сразу после операции - им также свойственны и существенные недостатки: синовиты, прогрессирующий остеолиз вокруг каналов в мыщелках большеберцовой и бедренной костей, низкая способность к трансформации и быстрое нарастание дегенеративно-дистрофических изменений в коленных суставах. Биологические протезы лишены этих недостатков. Однако использование алло- и ксенотрансплантатов имеет риск передачи инфекции, для них характерен более выраженный остеолиз костных каналов вследствие иммунной реакции и большее снижение механических свойств трансплантата, особенно в первые 6 мес, неконтролируемая биорезорбция и биодеградация, а также увеличение стоимости операции. Эти проблемы связаны прежде всего с недостаточным удалением биологической составляющей, на которую отвечает организм реципиента, или с разрушением коллагенового каркаса вследствие применения жестких методов химико-ферментативной обработки для удаления этих биокомпонентов из ткани [5]. Стоит обратить особое внимание на пластические материалы биологического ксеногенного происхождения, в основе которых находится естественный белок соединительной ткани - коллаген. Эти биологические материалы обладают высокой схожестью по структуре с замещаемыми тканями организма и очень доступны.

Наиболее перспективным направлением в замещении дефектов ткани в реконструктивной хирургии на сегодняшний день является разработка биоимплантатов на основе таких коллагенсодержащих биотканей, как децеллюляризованный ксеноперикард [6, 7]. Однако для протеза связки, в особенности крестообразной связки колена, требуется исходный материал с очень высокими изначальными прочностными характеристиками, способный выдерживать как минимум пороговые нагрузки, свойственные связкам, и по структуре наиболее сходный с ними, а также различную длину и площадь сечения для подбора клиницистами необходимых размеров протезируемого материала. Наиболее подходящим материалом по этим критериям являются сухожилия. Как уже было сказано, основными недостатками биологических материалов, в том числе и ксеногенного происхождения, являются способность к провоцированию воспаления и отторжению, а также к инфицированию из-за наличия чужеродных клеточных элементов и других биологических составляющих.

При создании ксенотрансплантатов снижение риска воспаления окружающих тканей и потенциального отторжения трансплантата является приоритетной задачей и требованием предимплантационной обработки донорской ткани. Одним из методов создания тканевых имплантов, применяемых в реконструктивно-восстановительной хирургии для улучшения репаративных процессов и обновления структурно-функциональных элементов в поврежденных тканях и органах, является девитализация донорской 


\section{AGTUAL ISSUES OF TRAMSPLANTATION}

ткани животных. Девитализация решает следующие задачи: предотвращение отторжения путем удаления либо разрушения клеток донора из имплантируемого образца (децеллюляризация), стабилизация структуры ткани (консервирование), сохранение адекватных биомеханических свойств и стерильность материала. Большинство способов получения тканевых биоимплантатов из ксеногенных тканей основаны на продолжительной обработке различными детергентно-энзимными и консервирующими растворами (глутаровый альдегид, эпоксисоединения), гипо- и гипертоническими растворами, действие которых связано с разрушением биологических компонентов ткани и ее структурной стабилизацией. Благодаря этим способам достигается продление функциональной полноценности тканевых биоимплантатов в постимплантационном периоде $[8,9]$.

Известны также способы обработки материала, в том числе говяжьего сухожилия, химикофризическими методами, включающими применение солевых растворов, замораживание и размораживание, замачивание в растворе перекиси водорода с воздействием последнего на поверхностно-активные вещества, погружение в сахарный сироп $[10,11]$. Стоит обратить отдельное внимание на использование сверхкритического флюида диоксида углерода $\left(\mathrm{CK} \Phi-\mathrm{CO}_{2}\right)$ совместно с поверхностно-активными веществами - детергентами (такими как додецилсульфат и Твин-80 с этиловым спиртом) для полноценного удаления органических составляющих с сохранением естественной архитектоники и прочностных свойств материала [12].

Метод сверхкритической фрлюидной экстракции является весьма перспективным известным подходом к децеллюляции ксеноматериала. СФК$\mathrm{CO}_{2}$, содержащий небольшое количество азеотропообразователя, является подходящей средой для извлечения ядер клеток и клеточных мембран из искусственной ткани. Он способен глубоко проникать в материал и воздействовать на клетки. В мягких условиях экстракции (15 МПа, $37^{\circ} \mathrm{C}$ ) ядра клеток удовлетворительно извлекаются из ткани в течение 1 ч. Напротив, эфрфективность удаления фросфолипидов сильно зависит от скорости переноса углекислого газа внутрь ткани. Механическая прочность ткани не снижалась даже при такой длительной обработке [13]. Для предотвращения передачи инфекций любые ксенотрансплантаты, применяемые в качестве медицинских изделий, необходимо стерилизовать. Ряд исследований, посвященных примене- нию СФК- $\mathrm{CO}_{2}$ в обработке биоматериала, свидетельствуют о его способности ко всему прочему и инактивировать многие штаммы патогенных микроорганизмов, вирусов и прионов, потенциально передаваемых от биоматериала человеку, что является большим преимуществом данного агента [14-16].

Цель исследования состоит в разработке методики качественной децеллюризации говяжьего сухожилия с сохранением и повышением его прочностных свойств.

\section{Материал и методы}

Въьбор съьвя

Говяжье сухожилие является доступным сырьем для производства медицинских имплантируемых изделий. Для изготовления протеза связки специально были отобраны сухожилия сгибателя и разгибателя пальца крупного рогатого скота, прошедшего ветеринарный контроль перед забоем, как наиболее подходящие по типоразмерам для решения поставленных клиницистами задач (рис. 1).

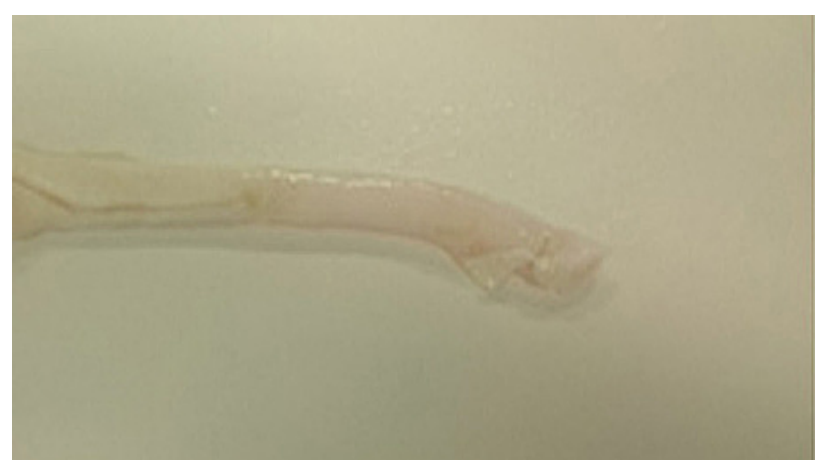

Рис. 1. Говяжье сухожилие разгибателя пальца до обработки

Fig. 1. Bovine toe extensor tendon before processing

Обработка

Сухожилия вырезали, отбирали равные участки со средним диаметром $0,5-1$ мм, механически очищали от внешних пленок, тщательно промывали в дистиллированной воде, нарезали на равные отрезки, а затем выдерживали в растворе хлористого натрия восходящей концентрации, далее тщательно промывали от соли, после чего дважды замораживали с оттаиванием при комнатной температуре, затем помещали в сахарный сироп, осушивали на нетканой салфетке, расправляли по направлению волокон, помещали в 


\section{AGTUAL ISSUES OF TRANSPLANTHTION}

эмульгатор Твин-80, извлекали и, не промывая, помещали в реактор установки сверхкритической фрлюидной экстракции, обрабатывали при заданном давлении и температуре, по окончании обработки материал извлекали из реактора, осушивали салфеткой по поверхности и помещали в $1 \%$ раствор перекиси водорода, промывали и погружали в $0,1 \%$ раствор глютарового альдегида, после чего вновь тщательно промывали под струей дистиллированной воды до полного прекращения пенистости, замораживали и высушивали в лиофильной сушке, а затем снова обрабатывали СФК-CO ${ }_{2}$ при заданном давлении и температуре.

После обработки сухожилие имело следующий вид (рис. 2).

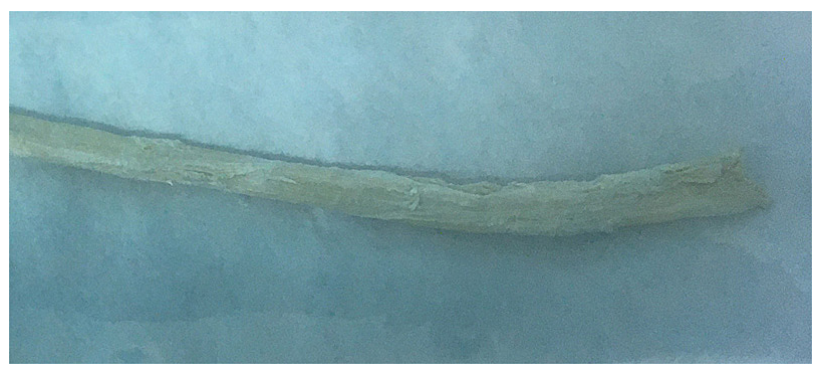

Рис. 2. Говяжье сухожилие после обработки

Fig. 2. Bovine tendon after processing

Материал испытывали по следующим критериям:

- наличие/отсутствие клеточных элементов;

- фризико-механические прочностные свойства.

Исследования на наличие клеточных элементов

Гистологически на наличие клеток были исследованы фрагменты говяжьего сухожилия размером 10х10 мм из необработанного и обработанного до этапа стабилизации в глутаровом альдегиде материала. Указанные исследования срезов из контрольных и прошедших обработку образцов производили методом фиксированных и окрашенных препаратов. Ткани фиксировали в нейтральном 7\% раствора фрормалина, проводили через батарею спиртов возрастающей концентрации и заливали в парафин. Парафиновые срезы толщиной 5-7 мкм окрашивали гематоксилином и эозином. Используя микроскоп с цифровой фотонасадкой Sony с разрешением 12 мегапикселей, из каждого гистологического препарата было получено по 5 микрофротографий с использованием программ Image View, Image Tool v.2.00, Image
Analyzer v.1.1. Таким образом был проведен анализ на наличие клеточных элементов. Из каждого образца микроскопически изучали поперечные срезы. Использовали увеличение в 200 раз.

Физико-механические свойства

Измерения производили на испытательной машине Instron 5900, производя не менее чем 20 повторов ( $\mathrm{n} \geq 20$ ) на разрыв. Прочностные характеристики материала измеряли по критерию Модуль Юнга в кгс/ мм² $^{2}$ Было проведено 5 серий экспериментов. Результаты измерений представлены в виде среднего и его стандартной ошибки. Статистическую значимость отличия определяли с использованием критерия Стьюдента. Были получены результаты прочностных свойств материала со статической значимостью, приведенные ниже $(\mathrm{p}<0,05)$.

Результаты

Исследование на наличие клетож

Гистологический анализ показал, что материал, не обработанный при окрашивании гематоксилином и эозином, включал клетки, преимущественно располагающиеся между пучками коллагеновых волокон. Между отдельными волокнами также встречались клетки, но в меньшем количестве. Во всех случаях клетки имели четкие контуры (рис. 3).

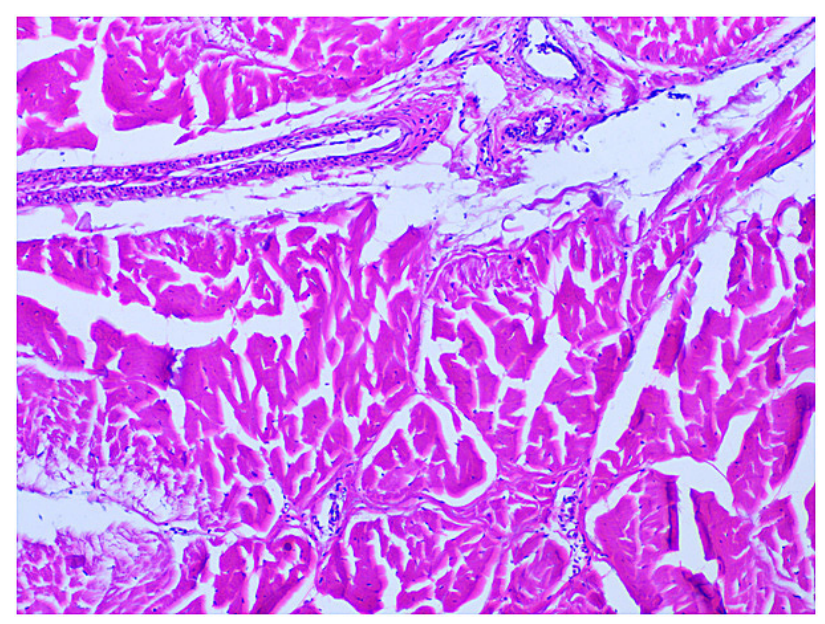

Рис. 3. Материал до обработки, окраска гематоксилином и эозином, поперечный срез, увеличение $\times 200$

Fig. 3. Material before processing, hematoxylin and eosin staining, cross section, (magnification, $\times 200$ ) 
Материал после обработки при окрашивании гематоксилином и эозином имел клетки, располагающиеся только между пучками коллагеновых волокон, в основном в области прохождения кровеносных сосудов, в количестве от 0 до 2 в поле зрения. Между отдельными волокнами клетки не встречались. Во всех случаях они имели размытые контуры, а частично были разрушены (рис. 4).

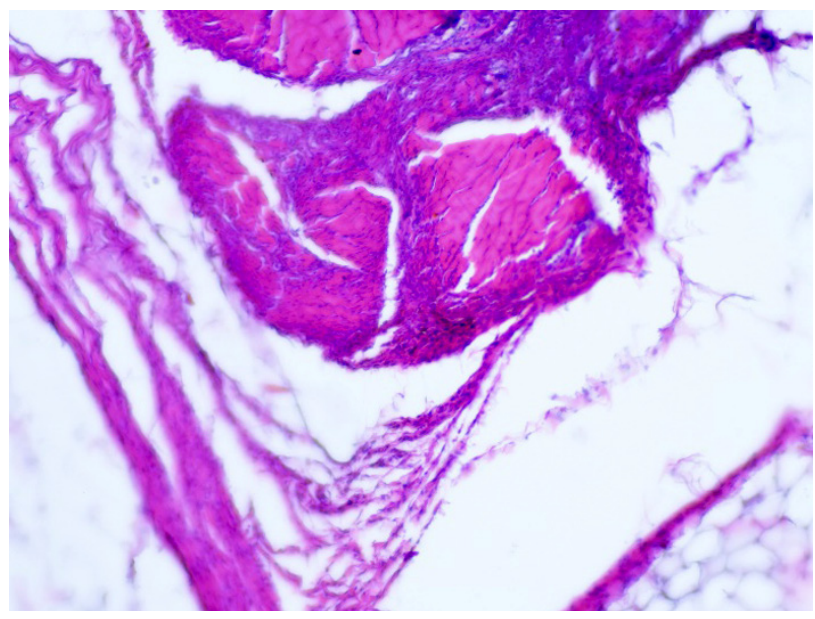

Рис. 4. Материал после обработки, окраска гематоксилином и эозином, поперечный срез, увеличение $\times 200$

Fig. 4. Material after processing, hematoxylin and eosin staining, cross section, (magnification, $\times 200$ )

Физико-механические свойства

Физико-механические и прочностные свойства материала до и после обработки от каждой группы в виде средних показаний группы образцов представлены в таблице.

Таблица. Результаты исследования физико-механических свойств материала

Table. The results of studying the physical and mechanical properties of the material

\begin{tabular}{|c|c|c|c|}
\hline Показатели & $\begin{array}{c}\text { Максимально } \\
\text { допустимая } \\
\text { нагрузка } \\
\text { на ПКС [2] }\end{array}$ & $\begin{array}{c}\text { До } \\
\text { обработки }\end{array}$ & $\begin{array}{c}\text { После } \\
\text { обработки }\end{array}$ \\
\hline $\begin{array}{l}\text { Модуль Юнга, } \\
\text { кгс/мм² }\end{array}$ & 170 & $503 \pm 7$ & $605 \pm 19$ \\
\hline
\end{tabular}

\section{Обсуждение}

Наличие/отсутствие клеток

Гистологическое исследование говяжьего сухожилия показывает, что после основных этапов его фризико-химической обработки (до использования консервации глутаровым альдегидом), направленных на децеллюляризацию материала и выведение биологически активных веществ, клеточных составляющих практически не остается, что в целом свидетельствует о достижении эфрфекта децеллюляризации.

Физико-леханические свойства

Как можно видеть из таблицы, после обработки прочность полученного материала на разрыв не снижалась и даже становилась выше, чем у необработанного материала, и в целом значительно превосходила максимально допустимую нагрузку для ПКС. Это связано, прежде всего, с применением щадящих режимов обработки (без агрессивных химических сред), сочетающих умеренное фризико-химическое воздействие на материал. Кроме того, повышение прочности материала можно также объяснить его стабилизацией в глутаровом альдегиде.

Заключение

Примененная методика обработки говяжьего сухожилия дает высокие результаты его децеллюляризации говяжьего сухожилия.

Прочностные характеристики говяжьего сухожилия после предложенной его обработки говяжьего сухожилия не теряются и даже имеют тенденцию к незначительному улучшению, связанному с этапом стабилизации материала в глутаровом альдегиде.

Предложенная методика обработки говяжьего сухожилия является перспективной для разработки протеза связки человека. Однако для оценки эфрфективности полученного материала требуется произвести дальнейшие исследования для изучения биологической безопасности и фрункциональных свойств на моделях in vitro и in vivo. 


\section{Литература}

1. Климов А.В., Глухов А.А. Повреждения передней крестообразной связки коленного сустава у спортсменов. Факторы риска и основные механизмы получения травм. Nova Info. ru. 2018;1(91):139-146. URL: https:// novainfo.ru/article/15767 [Дата обращения 7 октября 2020]

2. Евсеев В.И. Биомеханика повреждений коленного сустава. Москва: Русайн; 2018.

3. Лисицин М.П., Заремук А.М., Ткаченко Е.А., Бухарь С.В., Горевич И.И. Ревизионная хирургия передней крестообразной связки при ограничении разгибания в коленном суставе. Эндоскопическая хирургия. 2011;17(6):2930

4. Заяц В.В., Дулаев А.К., Дыдыкин А.В., Ульянченко И.Н., Коломойцев А.В., Ковтун А.В. Анализ эфреективности технологии артроскопической пластики передней крестообразной связки коленного сустава. Вестник хирургии им. И.И. Грекова. 2017;176(2):77-82.

5. Рыбин А.В., Кузнецов И.А., Румакин В.П., Нетылько Г.И., Ломая М.П. Экспериментально-морфологические аспекты несостоятельности сухожильных ауто- и аллотрансплантатов после реконструкции передней крестообразной связки коленного сустава в раннем послеоперационном периоде. Травматология и ортопедия России. 2016; $2(4): 60-75$

6. Белов Ю.В., Лысенко А.В., Леднев П.В., Салагаев Г.И. Применение заплаты из децеллюляризированного ксеноперикарда в хирургии бра- хиоцефальных артерий. Кардиология и сердечно-сосудистая хирургия. 2018;11(2):31-34.

7. Сиваконь С.В., Девин И.В., Сретенский С.В., Чиж А.А., Космынин Д.А. Результаты применения протезов из ксеноперикарда в хирургическом лечении подкожных дегенеративных разрывов ахиллова сухожилия. Современные проблемы науки и образования. 2015; 6. URL: https://science-education.ru/ru/ article/view?id=23291 [Дата обращения 7 октября 2020]

8. Манченко А.А., Михайлова И.П., Сандомирский Б.П. Морфология тканевой реакции у крыс при подкожной имплантации ксеноперикарда и створок аортального клапана свиньи, девитализированных криорадиационным методом. Клітинна та органна трансплантологія. 2016;4(1):30-38.

9. Сергеевичев Д.С., Сергеевичева В.В., Субботовская А.И., Васильева М.Б., Докучаева А.А., Краськов А.М. и др. Децеллюляризация как способ предотвращения активизации иммунного ответа на аллогенные легочные клапаны сердца. Гены и клетки. 2013;8(4):55-60. 10. Педросо Д., Эли М. Ксеногенные имплантаты мягких тканей и способы изготовления и использования. Патент RU 2665366. Заявка 2014150029 от 14.03.2013; опубликовано 29.08.2018. Бюл. №25. URL: https://patents. s3.yandex.net/RU2665366C2_20180829. pdf [Дата обращения 6 октября 2020]. 11. Бикбов M.M., Халимов А.Р., Зайнутдинова Г.Х., Кудоярова К.И., Лукьянова Е.Э. Способ получения транспланта- та для обталъмохирургии. Патент RU 2607185. Заявка 2015139247 от 15.09.2015; опубликовано 10.01.2017. Бюл. №1. URL: https://patents. s3.yandex.net/RU2607185C1_20170110. pdf [Дата обращения 6 октября 2020] 12. Бритиков Д.В., Чащин И.С., Хугаев Г.А., Бакулева Н.П. Девитализация аллографтов сверхкритическим диоксидом углерода и детергентами. Экспериментальная оценка. Бюллетень НЦССХ им. А.Н. Бакулева РАМН. 2019;20(5):402-409.

13. Sawada K, Terada D, Yamaoka $T$, Kitamura S, Fujisato T. Cell removal with supercritical carbon dioxide for acellular artificial tissue. Chem Technol Biotech. 2008;83(6):943-949. https://doi. org/10.1002/jctb.1899

14. Газизов Р.А., Шамсетдинов Ф.Н. Исследования инактивации Bacillusa trophaeus с использованием чистого и модифицированного сверхкритического диоксида углерода. Международный научно-исследовательский журнал. 2018;12-1(78):165-168.

15. Залепугин Д.Ю., Тилькунова Н.А., Чернышова И.В., Власов М.И. Стерилизация в сверхкритических средах. Сверхкритические фблюиды: Теория и практика. 2015;10(4):11-17.

16. Шадрин А.Ю., Мурзин А.А., Дормидонтова А.С., Суслов А.В., Суслова И.Н., Яровой Б.Ф. Действие сверхкритического $\mathrm{CO}_{2}$ на клетки микроорганизмов экстремофилов. Сверхкритические фблюиды: Теория и практика. 2009;4(2):29-33. 
1. Klimov AV, Glukhov AA. Povrezhdeniya perednej krestoobraznoj svyazki kolennogo sustava u sportsmenov. Faktory riska i osnovnye mehanizmy polucheniya travm. NovaInfo. ru. 2018;1(91):139-146. URL: https:// novainfo.ru/article/15767 [Accessed October 07, 2020] (In Russ.).

2. Evseev VI. Biomehanika povrezhdeniy kolennogo sustava. Moscow: Rusayn Publ.; 2018. (In Russ.).

3. Lisitsin MP, Zaremuk AM, Tkachenko EA, Bukhar SV, Gorevich II. Revision anterior cruciate ligament surgery for restriction of knee extension. Endoscopic surgery $=$ Endoskopicheskaya khirurgiya. 2011;17(6):29-30. (In Russ.).

4. Zayats VV, Dulaev AK, Dydykin AV., Ulyanchenko IN, Kolomoitsev AV, Kovtun AV. Analysis of efficacy of arthroscopic plasty technologies of anterior cruciform ligament of knee joint based on anatomical position of autograft. Grekov's Bulletin of Surgery. 2017;176(2):77-82. (In Russ.). https:// doi.org/10.24884/0042-4625-2017-1762-77-82

5. Rybin AV, Kuznetsov IA, Rumakin VP, Netylko GI, Lomaya MP. Experimental and morphological aspects of failed tendon auto- and allografts after acl reconstruction in early postoperative period. Traumatology and Orthopedics of Russia. 2016;22(4):60-75. (In Russ.). https://doi.org/10.21823/2311-29052016-22-4-60-75

6. Belov YuV, Lysenko AV, Lednev PV, Salagaev GI. Decellularized xenopericardial patch in supra-aortic vessels repair.

\section{References}

Russian Journal of Cardiology and Cardiovascular Surgery = Kardiologiya $i$ serdechno-sosudistaya khirurgiya. 2018;11(2):31-34. (In Russ.).

7. Sivakon SV, Devin IV, Sretensky SV, Chizh AA, Kosmynin DA. Results of application of xenopericardial prostheses in the surgical treatment of subcutaneous degenerative achilles tendon ruptures. Modern problems of science and education. 2015; 6. URL: https://scienceeducation.ru/ru/article/view?id=23291 [Accessed October 7, 2020] (In Russ.).

8. Manchenko AA, Mikhaylova IP, Sandomirskiy BP. Morfologiya tkanevoy reaktsii u krys pri podkozhnoy implantatsii ksenoperikarda i stvorok aortal'nogo klapana svin'i devitalizirovannykh krioradiatsionnym metodom. Klitinna ta organna transplantologiya. 2016;4(1):3038. (In Russ.).

9. Sergeevichev DS, Sergeevicheva VV, Subbotovskaya AI, Vasileva MB, Dokuchaeva A.A, Kraskov AM, et al. Decellyurizaciya kak sposob predotvrashcheniya aktivizacii immunnogo otveta na allogennye legochnye klapany serdca. Genesand Cells. 2013;8(4):55-60. (In Russ.).

10. Pedroso D, Eli M. Xenograft soft tissue implants and methods of making and using. Patent RU 2665366. Application 2014150029 from 14.03.2013; published on August 29, 2018. Bulletin No. 25. URL: https://patents.s3.yandex.net/ RU2665366C2_20180829.pdf [Accessed October 6, 2020] (In Russ.).

11. Bikbov MM, Khalimov AR, Zaynut- dinova GKh, Kudoyarova KI, Lukyanova EE. Method of producing xenograft for ophthalmosurgery. Patent RU 2607185. Application 2015139247 from 15.09.2015; published on 10.01.2017. Bul. No. 1. URL: https://patents.s3.yandex.net/ RU2607185C1_20170110.pdf [Accessed October 6, 2020] (In Russ.).

12. Britikov DV, Chashchin IS, Khugaev GA, Bakuleva NP. The decellularization of allografts with supercritical carbon dioxideand detergents. Experimental data. The Bulletin of Bakoulev Center Cardiovascular Diseases. 2019;20(5):402409. (In Russ.).

13. Sawada K, Terada D, Yamaoka $T$, Kitamura S, Fujisato T. Cell removal with supercritical carbon dioxide for acellular artificial tissue. Chem Technol Biotech. 2008;83(6):943-949. https://doi. org/10.1002/jctb.1899

14. Gazizov RA, Shamsetdinov FN. Study of adsorption of pure and modified supercritical carbon dioxide by polyethylene of medical purpose. International research journal. 2018;12-1(78):165-168. (In Russ.). 15. Zalepugin DYu, Tilkunova NA, Chernyshova IV, Vlasov MI. Sterilization in supercritical media. Sverhkriticheskie Fluidy: Teoriyai Praktika = Supercritical Fluids: Theory and Practice. 2015;10(4):11-17.

16. Shadrin AYu, Murzin AA, Dormidontova AS, Suslov AV, Suslova IN, Yarovoy BF. Effect of supercritical $\mathrm{CO}_{2}$ on extremophile cells. Sverhkriticheskie Fluidy: Teoriyai Praktika = Supercritical Fluids: Theory and Practice. 2009;4(2):29-33. (In Russ.). 


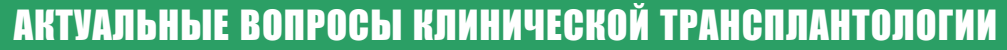

\section{AGTULL ISSUES OF TRMNSPLANTITION}

\section{Информация об авторах}

Максим Вячеславович Гурин

Алексей Александрович Венедиктов инженер-исследователь ООО «Кардиоплант», https://orcid.org/0000-0002-82344522

$70 \%$ - разработка концепции и дизайна исследования, оформление статьи

канд. биол. наук, управляющий ООО «Кардиоплант», https://orcid.org/0000-00031606-479X

30\% - проверка критически важного интеллектуального содержания

\section{Information about the authors}

Maksim V. Gurin

Aleksey A. Venediktov
Research Engineer, LLC "Cardioplant", https://orcid.org/0000-0002-8234-4522 $70 \%$, development of the study concept and design, article layout

Cand. Sci. (Biol.), Managing Director, LLC "Cardioplant", https://orcid.org/00000003-1606-479X

$30 \%$, reviewing the essential intellectual content
Статья поступила в редакцию 31.07.2020;

одобрена после рецензирования 02.09.2020;

принята к публикации 30.09.2020
The article was received on July 31, 2020; approved after reviewing September 2, 2020; accepted for publication September 30, 2020 